\title{
Effect of Diet on the Gut Microbiota Associated with Obesity
}

\author{
Bohkyung Kim', Ha-Neul Choi², Jung-Eun Yim*** \\ ${ }^{1}$ Department of Food Science and Nutrition, Pusan National University, Busan; ${ }^{2}$ Department of Food and Nutrition, Changwon National University, Changwon, \\ Korea
}

Obesity is abnormal or excessive fat accumulation that is associated with progression of metabolic diseases including type 2 diabetes mellitus, cardiovascular disease, nonalcoholic fatty liver disease, and cancer. Gut microbiota (GM) have received much attention as essential factors in development and progression of obesity. The diversity, composition, and metabolic activity of GM are closely associated with nutrient intake and dietary pattern. Scientific evidence supports the idea that dietary pattern directly changes the GM profile; therefore, diet is a crucial component related to interactions between GM and obesity progression. A literature review showed that dietary factors such as probiotics, prebiotics, fat, fatty acids, and fiber dramatically alter the GM profile related to obesity. Furthermore, different dietary patterns result in different GM composition and activity that can contribute to amelioration of obesity.

Key words: Diet, Prebiotics, Probiotics, Gastrointestinal microbiome, Obesity

\author{
Received July 31, 2019 \\ Reviewed August 24, 2019 \\ Accepted November 13, 2019 \\ *Corresponding author \\ Jung-Eun Yim \\ (i) \\ https://orcid.org/0000-0001-8344-1386 \\ Department of Food and Nutrition \\ Changwon National University, \\ 20 Changwondaehak-ro, Uichang-gu, \\ Changwon 51140, Korea \\ Tel: +82-55-213-3517 \\ Fax: +82-55-281-7480 \\ E-mail: jeyim@changwon.ac.kr
}

\section{INTRODUCTION}

Overweight and obesity have nearly tripled in the population since 1975. According to the World Health Organization (WHO), over 1.9 billion adults were considered overweight in 2014, representing $39 \%$ of the world's population. Over 340 million children and adolescents aged 5-19 years were also overweight or obese in 2016. Finkelstein et al. ${ }^{1}$ estimated an increase of 3.3 billion people with a body mass index $(\mathrm{BMI}) \geq 25.0 \mathrm{~kg} / \mathrm{m}^{2}$, corresponding to $57.8 \%$ of the adults worldwide by 2030 . Obesity is described as an accumulation of excessive fat mass concomitant with low-grade chronic systemic inflammation. ${ }^{2}$ Obesity has commonly been associated with development of other metabolic disorders such as type 2 diabetes mellitus (T2DM), cardiovascular disease (CVD), and some types of cancer. ${ }^{3,4}$
The gastrointestinal tract contains at least $10^{14}$ bacteria, with the most abundant numbers in the large intestine. ${ }^{5}$ The number of genes in the intestinal microbiome is 150 - to 500-fold greater than in human DNA. ${ }^{6}$ The collected gut microbiota (GM) are described as a "forgotten organ" that is sensitive to dietary, environmental, and host factors with function complicatedly intertwined with host metabolism. ${ }^{7}$ Both endogenous and exogeneous factors such as autoimmune disease, chronic disease, medications, antibiotics, smoking, stress level, and diet affect the diversity and composition of GM. Each individual has a unique GM composition and profile that may affect nutrient metabolism. Recent evidence has suggested that GM is a contributing factor in the progression of obesity. ${ }^{6,8,9}$ The GM is capable of modulating host metabolism through energy balance, chronic low-grade inflammation, and intestinal barrier function. ${ }^{6}$ Furthermore, the composition and diversity of GM are different

Copyright (C) 2019 Korean Society for the Study of Obesity

(a) This is an Open Access article distributed under the terms of the Creative Commons Attribution Non-Commercial License (http://creativecommons.org/licenses/by-nc/4.0/) which permits unrestricted non-commercial use, distribution, and reproduction in any medium, provided the original work is properly cited. 


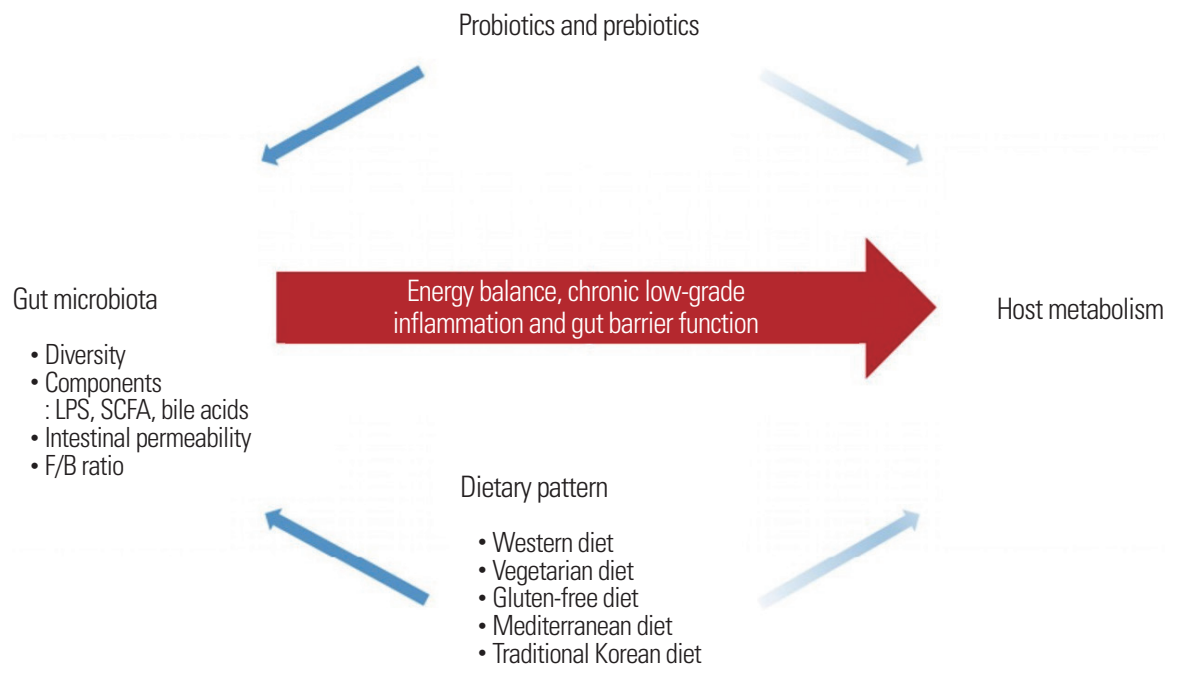

Figure 1. Effect of dietary factors on alteration of gut microbiota associated with host metabolism. LPS, lipopolysaccharide; SCFA, short chain fatty acid; F/B, Firmicutes/ Bacteroidetes.

between healthy weight and obese individuals. ${ }^{8}$ Therefore, the main objective of this review is to discuss whether GM altered by probiotics, prebiotics, and specific diet composition can contribute to amelioration of obesity (Fig. 1).

\section{ASSOCIATION BETWEEN OBESITY AND GM}

Obesity is a multifactorial, chronic disorder associated with other metabolic diseases. Recently, GM has received attention as a metabolic factor that affects the interactions between exogeneous factors and host metabolism. The GM is known to affect host metabolism by modulating energy balance, chronic-low grade inflammation, and gut barrier function. ${ }^{10}$ Modulation of these factors is highly associated with obesity; therefore, the GM is considered an environmental regulator of obesity. Several mechanisms of obesity and GM interactions have been suggested. The GM is comprised of a dynamic population of microorganisms including bacteria, archaea, fungi, and viruses. The dominant bacterial species in human GM are Bacteroidetes, Firmicutes, Actinobacteria, Proteobacteria, Fusobacteria, Cyanobacteria, and Verrucomicrobia. ${ }^{11}$ The microbiota profile depends on the host, and changes in GM diversity can contribute to host metabolism. Compositional changes in GM may disturb the homeostasis between host metabolism and GM. Many studies have investigated the relationship between GM and obesity and found that the number of Firmicutes was increased while the num- ber of Bacteroidetes decreased in obese animal and humans. ${ }^{12-14} \mathrm{Bac}-$ teroidetes have fewer genes involved in carbohydrate and lipid metabolism than Firmicutes. The increased Firmicutes/Bacteroidetes (F/ B) ratio plays a role in increasing energy storage in host adipose tissue by facilitating extraction of energy. ${ }^{13,15}$ In addition, GM usually exhibit low bacterial diversity in obese subjects. ${ }^{16}$ Therefore, the $\mathrm{F} /$ $\mathrm{B}$ ratio and resident bacteria of the intestine may contribute to development of obesity. Several human clinical trials have reported that a low level of Bifidobacteria is also involved in obesity. ${ }^{17}$ In both children and pregnant women, Staphylococcus aureus was associated with overweight, ${ }^{18}$ and Enterobacteriaceae were significantly increased with obesity. ${ }^{19,20}$

Development of obesity also has been linked to abnormal energy intake and expenditure. ${ }^{21}$ Increasing evidence suggests that energy balance (energy intake and expenditure) is highly intertwined and modulated by $\mathrm{GM}^{22} \mathrm{GM}$ can regulate energy intake and appetite by production of short-chain fatty acids (SCFAs) of nondigestible polysaccharides. ${ }^{23}$ The SCFAs, such as acetate, butyrate, and propionate, produced by bacterial fermentation act as substrates of energy as well as modulators of satiety and food consumption when they combine with G-protein coupled receptor 41 (GPR41) and GPR43 in intestinal epithelial cells. ${ }^{24,25}$ The SCFAs also stimulate secretion of peptide YY (PYY) and glucagon-like peptide-1 (GLP-1), which can suppress intestinal mobility transit allowing higher uptake of nutrients. $^{23,25}$ 


\section{INTESTINAL PERMEABILITY}

Many environmental factors such as diet, energy intake, and exercise can dramatically influence GM. ${ }^{26,27}$ Specific foods and diets can influence the abundance of different bacteria in the GM, which can affect host health. Probiotics can increase GM diversity and SCFA production and reduce T2DM and CVD. Several suggested mechanisms linking microbiota to weight changes include an increased capacity of some bacteria to extract energy, improved transfer of calories from food to host, and changes in host absorption metabolism

\section{PREBIOTICS AND GM}

Prebiotics have been defined by the Food and Agriculture Organization (FAO) of the United Nations and WHO as "non-digestible food ingredients that beneficially affect the host by selectively stimulating the growth and/or activity of one or a limited number of bacterial species already established in the colon, and thus improve the host health." ${ }^{28}$ As mentioned above, dietary prebiotics have typically been classified as nondigestible fiber that passes undigested through the upper gastrointestinal tract and stimulates and colonizes the growth of beneficial microorganisms. ${ }^{29}$ Bindels et al. ${ }^{30}$ reported that prebiotic ingredients include inulin, fructooligosaccharides (FOS), galactooligosaccharides, and human milk oligosaccharides. The prebiotics usually found in fruits and vegetables may lead to various health benefits in the host. ${ }^{31}$ Among the advantages of prebiotics are promotion of ion and trace element absorption such as that of calcium, iron, and magnesium and immune system regulation by increasing Immunoglobulin A production and modulating cytokine production through mechanisms mediated by microbial metabolic products. ${ }^{29}$ Prebiotics selectively stimulate the growth of Bifidobacteria and Lactobacillus species, which can produce greater microbial diversity within the microbiome. Through stimulation by beneficial microbiota and following fermentation, these prebiotic substrates manufacture SCFAs such as butyrate, propionate, and acetate, which are the primary energy sources of the intestine and have metabolic effects on the host. Prebiotic effects on regulation of satiety and food consumption are due to production of higher SCFA level, which improves GLP-1, PYY, and ghrelin production. ${ }^{32}$ In addition, prebiotics also have anti-obesity effects involved in improvement of lipid metabolism by modulated GM composition. ${ }^{33-35}$ Oligofructose-treated animals showed lower triglyceride level and adipose tissue mass. ${ }^{36}$ Short-chain FOS treatment also ameliorates plasma lipid metabolism and hyperinsulinemia, which are associated with changes in GM composition in diet-induced obese mice. ${ }^{36}$ Nihei et al. ${ }^{37}$ also found that supplementation with $\alpha$-cyclodextrins showed modulation of GM and SCFA production in diet-induced obese mice. These effects were associated with modulation in gene expression of lipid metabolism, including upregulation of peroxisome proliferator-activated receptor $\gamma$ (PPAR- $\gamma$ ) and PPAR- $\alpha$ and downregulation of sterol regulatory element-binding protein-1c and fatty acid synthase. ${ }^{37}$ Several clinical trials have shown a strong association between prebiotic-altered GM and obesity (Table 1). ${ }^{38-43}$

\section{PROBIOTICS AND GM IN OBESITY}

According to $\mathrm{FAO} / \mathrm{WHO}$, probiotics are "live microorganisms which confer a health benefit on the host when administered in adequate amounts. ${ }^{22}$ Recent studies have shown that Bifidobacterium (B. breve B3, B. infantis, and B. longum) and Lactobacillus (L. rhamnosus, L. casei strain Shirota [LAB13], L. gasseri, and L. plantarum) species have been used as probiotic treatments in obese animal models due to a lack of pathogenicity and reduced antibiotic resistance. ${ }^{33}$ In fact, many studies have reported that animals fed with the above-mentioned strains of Lactobacillus and Bifidobacterium showed suppression of weight gain, fat depots, and white adipose tissue compared to placebo-treated control animals. However, experimental studies clearly differ in both experimental duration and daily probiotic dose administration, which lead to different effects on body weight and/or fat mass. These probiotics showed antiobesity effects through beneficial changes in GM, lower insulin resistance, and higher satiety by modulation of the mechanism.

The effects of Lactobacillus and Bifidobacterium strains, alone or in combination, have also been well-described in obese adults, leading to reduced body weight, waist circumference, and fat depots. ${ }^{44-50}$ Clinical studies have shown that the anti-obesogenic effects of probiotics are due to both the probiotic dose and experimental duration. L. gasseri (SBT2055 and BNR17) treatment showed reduced 
Table 1. Clinical trials on the association between prebiotics and obesity

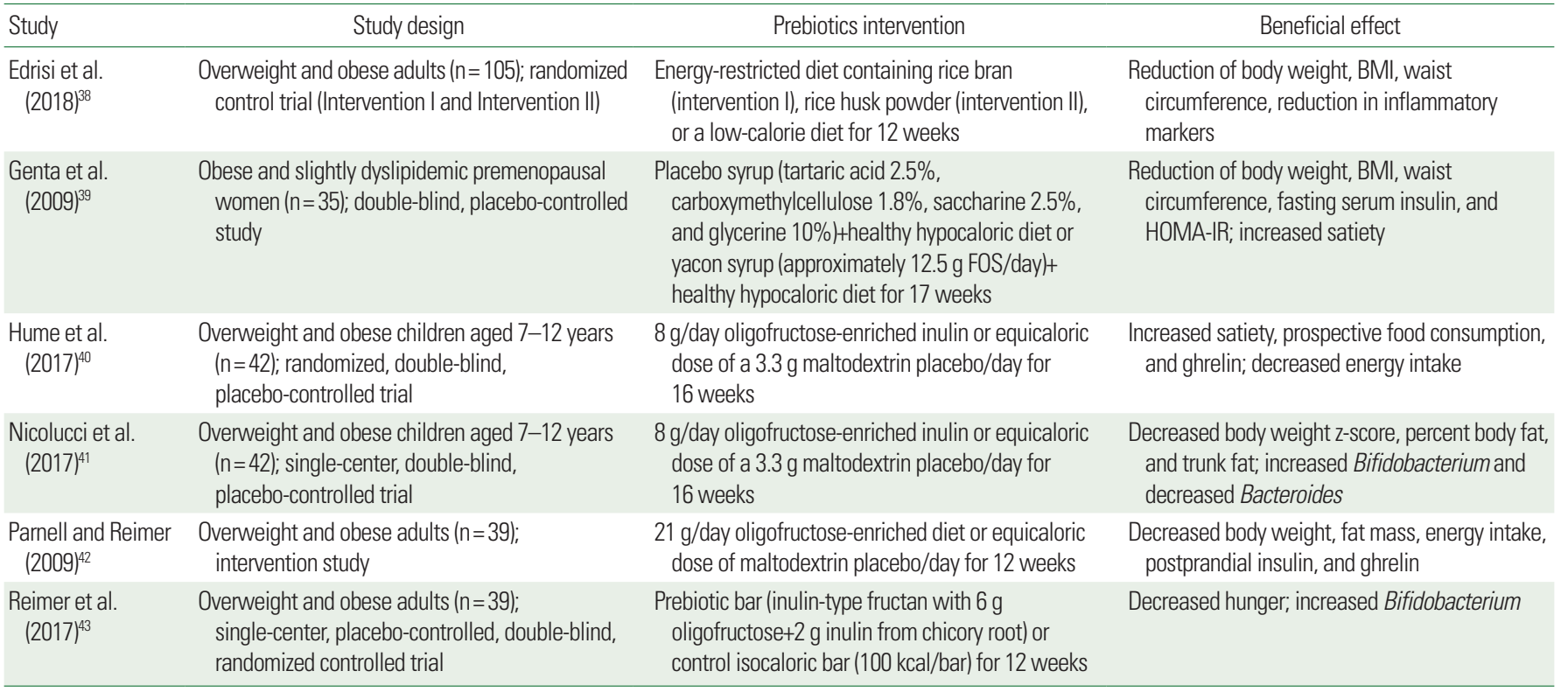

BMI, body mass index; FOS, fructooligosaccharides; HOMA-IR, homeostasis model assessment of insulin resistance.

visceral adipose tissue and waist circumference in adults with obese tendencies or obesity. ${ }^{46,47}$ Pedret et al. ${ }^{48}$ reported that Bifidobacterium animalis subspecies. Lactis CECT 8145 intervention significantly reduced waist circumference, waist circumference/height ratio, and BMI. The therapy based on L. rhamnosus CGMCC1.3724 showed weight loss in obese women in comparison with obese men. ${ }^{49}$ High- and low-doses of probiotic mixtures (different strains of Lactobacillus and Bifidobacterium) showed similar beneficial effects on weight, BMI, and body fat mass in obese postmenopausal women, but only the high-dose group showed improvement in lipid profile. ${ }^{50}$ In these findings, the efficacy of probiotic treatment in human studies is still unclear due to small cohort studies and shortterm follow-up. Thus, further studies are needed to identify selective probiotic strains that may produce effective changes in weight or body fat loss, either alone or in combination with other probiotic strains (Table 2). ${ }^{44-50}$

\section{INFLUENCE OF DIET ON GM IN OBESITY}

Diet is one of the critical factors in progression of obesity and is profoundly linked to GM composition. ${ }^{51}$ Nutrient intake and eating habits directly influence the composition, diversity, and metabolism of GM. ${ }^{51,52}$ Furthermore, the composition and functionality of GM respond quickly to changes in dietary composition. Several studies showed that, within 2 days after the start the dietary intervention, the GM responded and exerted changes in composition. ${ }^{53}$ Interestingly, a healthy dietary pattern related to GM profiles exerted protective effects against development of diabetes in obese individuals. ${ }^{54}$ Therefore, a balanced diet is required to maintain the composition and proper function of the GM. Many dietary patterns such as Western diet, vegetarian diet, gluten-free diet, and the Mediterranean diet have been shown to affect the distinct diversity of the GM that may affect host metabolism. ${ }^{52}$

The Western diet consists of high intake of saturated fats, refined grains, sugar, salt, and high fructose corn syrup and a low intake of fiber. It is highly associated with obesity and metabolic disease. The Western diet promotes inflammation and changes the profile of the GM from healthy to the obese pattern. ${ }^{55}$ It also has been shown to decrease the total bacteria amount as well as the beneficial Lactobacillus species (sp.) and Bifidobacterium sp. in the gut. ${ }^{15}$

Vegetarian and vegan diets consist of plant-based foods and are rich in dietary fiber, in contrast with the Western diet. Abundant fiber in these diets promotes stable GM profile and increases the presence of lactic acid bacteria. ${ }^{56}$ Both the vegetarian and vegan diet were shown to lower Bacteroides sp. and Bifidobacterium sp. The GM profile of the vegan diet exerted an increase in the abun- 
Table 2. Clinical trials on the association between probiotics and obesity

\begin{tabular}{|c|c|c|c|}
\hline Study & Study design & Probiotics intervention & Beneficial effect \\
\hline $\begin{array}{l}\text { Gomes et al. } \\
(2017)^{44}\end{array}$ & $\begin{array}{l}\text { Obese women aged } 20-59 \text { years }(\mathrm{n}=43) \text {; } \\
\text { randomized, double-blind, placebo-controlled } \\
\text { intervention, clinical trials }\end{array}$ & $\begin{array}{l}\text { Lactobacillus acidophilus, Lactobacillus casei } \\
\text { Lactococcus lactis, Bifidobacterium bifidum, } \\
\text { Bifidobacterium lactis }\left(2 \times 10^{10} \mathrm{CFU} / \text { day), or a }\right. \\
\text { placebo for } 8 \text { weeks }\end{array}$ & Reduction of waist circumference \\
\hline $\begin{array}{l}\text { Higashikawa et al. } \\
(2016)^{45}\end{array}$ & $\begin{array}{l}\text { Overweight adults aged } 20-70 \text { years }(n=62) \text {; } \\
\text { randomized, double-blind, placebo-controlled } \\
\text { clinical trial }\end{array}$ & $\begin{array}{l}10^{11} \mathrm{CFU} / \text { day of living or heat-killed Pediococcus } \\
\text { pentosaceus with dietary intervention or a place- } \\
\text { bo for } 12 \text { weeks }\end{array}$ & Reduction of BMl after heat-killed LP28 \\
\hline $\begin{array}{l}\text { Kadooka et al. } \\
(2010)^{46}\end{array}$ & $\begin{array}{l}\text { Adults with overweight and obesity } \\
\left.\text { (BMl between } 24.2 \text { and } 30.7 \mathrm{~kg} / \mathrm{m}^{2}, \mathrm{n}=87\right) \text {; } \\
\text { multicenter, double-blind, randomized, placebo- } \\
\text { controlled intervention trial }\end{array}$ & $\begin{array}{l}200 \mathrm{~g} / \text { day of fermented milk containing } \\
\text { Lactobacillus gasseri }\left(5 \times 10^{10} \mathrm{CFU} / 100 \mathrm{~g}\right. \\
\text { fermented milk) or } 200 \mathrm{~g} / \text { day of fermented milk } \\
\text { without probiotic for } 12 \text { weeks }\end{array}$ & $\begin{array}{l}\text { Reduction of body weight, BMl, and fat areas } \\
\text { including abdominal visceral and } \\
\text { subcutaneous fat }\end{array}$ \\
\hline $\begin{array}{l}\text { Kim et al. } \\
(2018)^{47}\end{array}$ & $\begin{array}{l}\text { Obese adults aged } 20-75 \text { years }(\mathrm{n}=90) \text {; } \\
\text { randomized, double-blind, placebo-controlled } \\
\text { trial-controlled trial }\end{array}$ & $\begin{array}{l}\text { Low }\left(10^{9} \mathrm{CFU} / \text { day) and high (1010 } \mathrm{CFU} / \text { twice a day) }\right. \\
\text { dose of L. gasseri+or placebo for } 12 \text { weeks }\end{array}$ & $\begin{array}{l}\text { Decreased waist circumferences in low dose; } \\
\text { decreased visceral adipose tissue in high dose }\end{array}$ \\
\hline $\begin{array}{l}\text { Pedret et al. } \\
(2019)^{48}\end{array}$ & $\begin{array}{l}\text { Abdominally obese randomized, parallel, } \\
\text { double-blind, placebo-controlled trial adults } \\
(\mathrm{n}=126)\end{array}$ & $\begin{array}{l}10^{10} \mathrm{CFU} / \mathrm{cap} / \text { day of Bifidobacterium animalis } \\
\text { subsp. Lactis CECT } 8145 \text { or its heat-killed form or } \\
\text { placebo for } 12 \text { weeks }\end{array}$ & $\begin{array}{l}\text { Reduction in BMI and the ratio of waist } \\
\text { circumference/height }\end{array}$ \\
\hline $\begin{array}{l}\text { Sanchis-Chordà et al. } \\
(2019)^{49}\end{array}$ & $\begin{array}{l}\text { Obese adults aged } 18-55 \text { years }(n=125) \text {; } \\
\text { randomized, double-blind, placebo-controlled } \\
\text { trial }\end{array}$ & $\begin{array}{l}1.62 \times 10^{8} \mathrm{CFU} / 2 \mathrm{cap} / \text { day of Lactobacillus } \\
\text { rhamnosus or } 250 \mathrm{mg} \text { of maltodextrin+3 } \mathrm{mg} \\
\text { magnesium stearate for } 12 \text { weeks }\end{array}$ & Reduction in weight \\
\hline $\begin{array}{l}\text { Szulińska et al. } \\
(2018)^{50}\end{array}$ & $\begin{array}{l}\text { Obese postmenopausal women aged } \\
45-70 \text { years }(n=81) \text {; randomized-double-blind, } \\
\text { placebo-controlled clinical trial }\end{array}$ & $\begin{array}{l}\text { Probiotic mixture including different Lactobacillus } \\
\text { and Bifidobacterium strains in low dose ( } 2.5 \times \\
10^{9} \mathrm{CFU} / \text { day) and high dose }\left(10^{10} \mathrm{CFU} / \text { day/two }\right. \\
\text { sachets per day) or placebo for } 12 \text { weeks }\end{array}$ & $\begin{array}{l}\text { Reduction in body weight, BMl, and fat mass in } \\
\text { both low dose and high dose groups; } \\
\text { improvement of lipid profiles in the high dose } \\
\text { group }\end{array}$ \\
\hline
\end{tabular}

CFU, colony-forming unit; BMI, body mass index; subsp., subspecies.

dance of protective microbiota. ${ }^{57}$ Additionally, abundant polyphenol (e.g., from tea, coffee, berries, and vegetables such as artichokes, olives, and asparagus) content in these diets exerted increases in intestinal barrier protectors (Bifidobacterium and Lactobacillus), butyrate-producing bacteria (Faecalibacterium prausnitzii and Roseburia), Bacteroides vulgatus, and Akkermansia muciniphila. It also decreased lipopolysaccharide producers (Escherichia coli and Enterobacter cloacae) that can induce inflammation.

The effects of a gluten-free diet on the GM is well known since gluten-related disease is closely associated with GM profile and metabolism. ${ }^{58}$ The gluten-free diet lowered the abundance of Bifidobacterium sp., Lactobacillus sp. ${ }^{59}$ and Ruminococcus bromii and Roseburia faecis, whereas the Victivallaceae and Clostridiaceae were increased. ${ }^{58,60}$ Poorly digested fermentable carbohydrates (fermentable oligo-, di-, mono-saccharides, and polyols [FODMAPs]) are known to increase digestive problems and cause irritable bowel syndrome; therefore, a low FODMAP diet is used clinically to reduce intestinal symptoms. The diversity and metabolism of GM significantly changed by the FODMAP diet. The low FODMAP diet reduced the total GM count as well as the number of bacteria involved in gas production. GM alteration by the low FODMAP diet exerted an increase in Actinobacteria and a decrease in Bifidobacterium. ${ }^{61,62}$

The Mediterranean diet consists of vegetables, olive oil, and fruits, a moderate intake of poultry, and a low intake of red meat and dairy products. It is well known as one of the healthiest dietary patterns. GM composition in the Mediterranean diet is high in Lactobacillus, Bifidobacterium, and Prevotella that is closely associated with the prevention of obesity and improvement of lipid and cholesterol profiles. Furthermore, the Mediterranean diet lowered Clostridium sp. that can induce inflammation. ${ }^{63}$ The Mediterranean diet provides high dietary fiber and polyunsaturated fatty acid (PUFA) content. Dietary fatty acids can also affect GM composition. The consumption of n-3 PUFAs and conjugated linoleic acid exerted beneficial effects on the GM compared to that of n-6 PUFAs and saturated fatty acids. The GM profile in obesity changed, and was similar to that of normal individuals, by n-3 PUFA consumption. ${ }^{64}$

The prevalence of obesity dramatically increased to $40 \%$ according to the data from the 2015 Korea National Health and Nutrition Examination Survey for Korean adults. ${ }^{65}$ Dietary pattern and lifestyle changed dramatically with the rapid industrialization in Korea 
Table 3. The effect of diet on GM associated with obesity

\begin{tabular}{|c|c|}
\hline Diet & Effect on GM associated obesity \\
\hline $\begin{array}{l}\text { Western diet: high intake of saturated fat, refined grains, } \\
\text { sugars, salt, and high fructose corn syrup and low intake of } \\
\text { fiber }{ }^{15,55}\end{array}$ & $\begin{array}{l}\text { Promotes inflammation and changes the GM profile to the obese pattern } \\
\text { Decrease in total GM amount } \\
\text { Decrease in beneficial Lactobacillus sp. and Bifidobacterium sp. }\end{array}$ \\
\hline $\begin{array}{l}\text { Vegetarian and vegan diets: plant-based foods and rich in } \\
\text { dietary fiber }{ }^{56,57}\end{array}$ & $\begin{array}{l}\text { Increase in the abundance of protective microbiota } \\
\text { Increase in intestinal barrier protectors (Bifidobacteria and Lactobacillus), increase in butyrate-producing bacteria } \\
\text { (Faecalibacterium prausnitzii and Roseburia) } \\
\text { Decrease in inflammation-inducing lipopolysaccharide producers (Escherichia coliand Enterobacter cloacae) } \\
\rightarrow \text { prevents obesity }\end{array}$ \\
\hline Gluten-free diet ${ }^{58,59}$ & $\begin{array}{l}\text { Decrease in Bifidobacterium sp., Lactobacillus sp., Ruminococcus bromii, and Roseburia faecis } \\
\text { Increase in Victivallaceae and Clostridiaceae }\end{array}$ \\
\hline $\begin{array}{l}\text { Mediterranean diet: consists of vegetables, olive oil, fruits, a } \\
\text { moderate intake of poultry, and a low intake of red meat and } \\
\text { dairy products }^{63,64}\end{array}$ & $\begin{array}{l}\text { Increase in Lactobacillus, Bifidobacterium, and Prevotella } \\
\rightarrow \text { prevents obesity and improves lipid and cholesterol profiles } \\
\text { Decrease in Clostridium that can induce inflammation. }\end{array}$ \\
\hline $\begin{array}{l}\text { Korean traditional diet: high consumption of vegetables and } \\
\text { fermented foods, moderate intake of legumes and fish }{ }^{65,66}\end{array}$ & $\begin{array}{l}\text { Increase in Bacteroides (Bacteroidaceae) and Bifidobacterium (Bifidobacteriaceae-Actinobacteria) } \\
\text { Decrease in Prevotella (Prevotellaceae) } \\
\rightarrow \text { prevents obesity }\end{array}$ \\
\hline
\end{tabular}

GM, gut microbiota; sp., species.

over the last several decades. The consumption of Western food and less physical activity increased obesity and metabolic diseases. The traditional Korean dietary pattern is high in consumption of vegetables and fermented foods, with moderate intake of legumes and fish. Compared to the animal-based Western diet, this plantbased diet altered high levels of Bacteroides (Bacteroidaceae) and Bifidobacterium (Bifidobacteriaceae-Actinobacteria) and lower levels of Prevotella (Prevotellaceae). The decrease of Bacteroides (Bacteroidaceae) and increase of Prevotella (Prevotellaceae) showed a higher risk for obesity (Table 3). ${ }^{15,55-59,63-66}$

\section{CONCLUSION}

The diversity, composition, and metabolic activity of the GM are closely associated with nutrient intake and dietary pattern. Specific dietary factors and dietary patterns alter the GM profiles that can regulate or affect progression of obesity. More studies and longterm trials are needed to understand the effects of dietary pattern on alteration of the GM associated with obesity.

\section{CONFLICTS OF INTEREST}

The authors declare no conflict of interest.

\section{AUTHOR CONTRIBUTIONS}

Review concept and design: JEY, BK; drafting of the manuscript: BK, HNC; critical revision of the manuscript: JEY.

\section{REFERENCES}

1. Finkelstein EA, Khavjou OA, Thompson H, Trogdon JG, Pan L, Sherry B, et al. Obesity and severe obesity forecasts through 2030. Am J Prev Med 2012;42:563-70.

2. Zeyda M, Stulnig TM. Obesity, inflammation, and insulin resistance: a mini-review. Gerontology 2009;55:379-86.

3. Aballay LR, Eynard AR, Díaz Mdel P, Navarro A, Muñoz SE. Overweight and obesity: a review of their relationship to metabolic syndrome, cardiovascular disease, and cancer in South America. Nutr Rev 2013;71:168-79.

4. Abate N. Obesity and cardiovascular disease: pathogenetic role of the metabolic syndrome and therapeutic implications. J Diabetes Complications 2000;14:154-74.

5. Booijink CC, Zoetendal EG, Kleerebezem M, de Vos WM. Microbial communities in the human small intestine: coupling diversity to metagenomics. Future Microbiol 2007;2:285-95.

6. Sonnenburg JL, Bäckhed F. Diet-microbiota interactions as moderators of human metabolism. Nature 2016;535:56-64. 
7. O'Hara AM, Shanahan F. The gut flora as a forgotten organ. EMBO Rep 2006;7:688-93.

8. Castaner O, Goday A, Park YM, Lee SH, Magkos F, Shiow $\mathrm{ST}$, et al. The gut microbiome profile in obesity: a systematic review. Int J Endocrinol 2018;2018:4095789.

9. Khan MJ, Gerasimidis K, Edwards CA, Shaikh MG. Role of gut microbiota in the aetiology of obesity: proposed mechanisms and review of the literature. J Obes 2016;2016:7353642.

10. Kobyliak N, Conte C, Cammarota G, Haley AP, Styriak I, Gaspar L, et al. Probiotics in prevention and treatment of obesity: a critical view. Nutr Metab (Lond) 2016;13:14.

11. Arumugam M, Raes J, Pelletier E, Le Paslier D, Yamada T, Mende DR, et al. Enterotypes of the human gut microbiome. Nature 2011;473:174-80.

12. Koliada A, Syzenko G, Moseiko V, Budovska L, Puchkov K, Perederiy V, et al. Association between body mass index and Firmicutes/Bacteroidetes ratio in an adult Ukrainian population. BMC Microbiol 2017;17:120.

13. Mariat D, Firmesse O, Levenez F, Guimarăes V, Sokol H, Doré J, et al. The Firmicutes/Bacteroidetes ratio of the human microbiota changes with age. BMC Microbiol 2009;9:123.

14. Greenhill C. Gut microbiota: Firmicutes and Bacteroidetes involved in insulin resistance by mediating levels of glucagon-like peptide 1. Nat Rev Endocrinol 2015;11:254.

15. Bell DS. Changes seen in gut bacteria content and distribution with obesity: causation or association? Postgrad Med 2015;127: 863-8.

16. Baothman OA, Zamzami MA, Taher I, Abubaker J, Abu-Farha M. The role of Gut Microbiota in the development of obesity and Diabetes. Lipids Health Dis 2016;15:108.

17. Stephens RW, Arhire L, Covasa M. Gut microbiota: from microorganisms to metabolic organ influencing obesity. Obesity (Silver Spring) 2018;26:801-9.

18. Collado MC, Isolauri E, Laitinen K, Salminen S. Distinct composition of gut microbiota during pregnancy in overweight and normal-weight women. Am J Clin Nutr 2008;88:894-9.

19. Balamurugan R, George G, Kabeerdoss J, Hepsiba J, Chandragunasekaran AM, Ramakrishna BS. Quantitative differences in intestinal Faecalibacterium prausnitzii in obese Indian children. Br J Nutr 2010;103:335-8.
20. Santacruz A, Collado MC, García-Valdés L, Segura MT, MartínLagos JA, Anjos T, et al. Gut microbiota composition is associated with body weight, weight gain and biochemical parameters in pregnant women. Br J Nutr 2010;104:83-92.

21. Hill JO, Wyatt HR, Peters JC. Energy balance and obesity. Circulation 2012;126:126-32.

22. Sivamaruthi BS, Kesika P, Suganthy N, Chaiyasut C. A review on role of microbiome in obesity and antiobesity properties of probiotic supplements. Biomed Res Int 2019;2019:3291367.

23. Chambers ES, Preston T, Frost G, Morrison DJ. Role of gut microbiota-generated short-chain fatty acids in metabolic and cardiovascular health. Curr Nutr Rep 2018;7:198-206.

24. Kim MH, Kang SG, Park JH, Yanagisawa M, Kim CH. Shortchain fatty acids activate GPR41 and GPR43 on intestinal epithelial cells to promote inflammatory responses in mice. Gastroenterology 2013;145:396-406.

25. Ang Z, Ding JL. GPR41 and GPR43 in obesity and inflammation: protective or causative? Front Immunol 2016;7:28.

26. Conlon MA, Bird AR. The impact of diet and lifestyle on gut microbiota and human health. Nutrients 2014;7:17-44.

27. Rosenbaum M, Knight R, Leibel RL. The gut microbiota in human energy homeostasis and obesity. Trends Endocrinol Metab 2015;26:493-501.

28. Linares DM, Ross P, Stanton C. Beneficial microbes: the pharmacy in the gut. Bioengineered 2016;7:11-20.

29. Holscher HD. Dietary fiber and prebiotics and the gastrointestinal microbiota. Gut Microbes 2017;8:172-84.

30. Bindels LB, Delzenne NM, Cani PD, Walter J. Towards a more comprehensive concept for prebiotics. Nat Rev Gastroenterol Hepatol 2015;12:303-10.

31. Hutkins RW, Krumbeck JA, Bindels LB, Cani PD, Fahey G Jr, Goh YJ, et al. Prebiotics: why definitions matter. Curr Opin Biotechnol 2016;37:1-7.

32. Cerdó T, García-Santos JA, G Bermúdez M, Campoy C. The role of probiotics and prebiotics in the prevention and treatment of obesity. Nutrients 2019;11:E635.

33. Barengolts E. Gut microbiota, prebiotics, probiotics, and synbiotics in management of obesity and prediabetes: review of randomized controlled trials. Endocr Pract 2016;22:1224-34.

34. Nicolucci AC, Reimer RA. Prebiotics as a modulator of gut 
microbiota in paediatric obesity. Pediatr Obes 2017;12:265-73.

35. Delzenne NM, Neyrinck AM, Bäckhed F, Cani PD. Targeting gut microbiota in obesity: effects of prebiotics and probiotics. Nat Rev Endocrinol 2011;7:639-46.

36. Cluny NL, Eller LK, Keenan CM, Reimer RA, Sharkey KA. Interactive effects of oligofructose and obesity predisposition on gut hormones and microbiota in diet-induced obese rats. Obesity (Silver Spring) 2015;23:769-78.

37. Nihei N, Okamoto H, Furune T, Ikuta N, Sasaki K, Rimbach G, et al. Dietary $\alpha$-cyclodextrin modifies gut microbiota and reduces fat accumulation in high-fat-diet-fed obese mice. Biofactors $2018 ; 44: 336-47$.

38. Edrisi F, Salehi M, Ahmadi A, Fararoei M, Rusta F, Mahmoodianfard S. Effects of supplementation with rice husk powder and rice bran on inflammatory factors in overweight and obese adults following an energy-restricted diet: a randomized controlled trial. Eur J Nutr 2018;57:833-43.

39. Genta S, Cabrera W, Habib N, Pons J, Carillo IM, Grau A, et al. Yacon syrup: beneficial effects on obesity and insulin resistance in humans. Clin Nutr 2009;28:182-7.

40. Hume MP, Nicolucci AC, Reimer RA. Prebiotic supplementation improves appetite control in children with overweight and obesity: a randomized controlled trial. Am J Clin Nutr 2017; 105:790-9.

41. Nicolucci AC, Hume MP, Martínez I, Mayengbam S, Walter J, Reimer RA. Prebiotics reduce body fat and alter intestinal microbiota in children who are overweight or with obesity. Gastroenterology 2017;153:711-22.

42. Parnell JA, Reimer RA. Weight loss during oligofructose supplementation is associated with decreased ghrelin and increased peptide YY in overweight and obese adults. Am J Clin Nutr 2009;89:1751-9.

43. Reimer RA, Willis HJ, Tunnicliffe JM, Park H, Madsen KL, Soto-Vaca A. Inulin-type fructans and whey protein both modulate appetite but only fructans alter gut microbiota in adults with overweight/obesity: a randomized controlled trial. Mol Nutr Food Res 2017;61:1700484.

44. Gomes AC, de Sousa RG, Botelho PB, Gomes TL, Prada PO, Mota JF. The additional effects of a probiotic mix on abdominal adiposity and antioxidant Status: a double-blind, random- ized trial. Obesity (Silver Spring) 2017;25:30-8.

45. Higashikawa F, Noda M, Awaya T, Danshiitsoodol N, Matoba Y, Kumagai T, et al. Antiobesity effect of Pediococcus pentosaceus LP28 on overweight subjects: a randomized, double-blind, placebo-controlled clinical trial. Eur J Clin Nutr 2016;70:582-7. 46. Kadooka Y, Sato M, Imaizumi K, Ogawa A, Ikuyama K, Akai Y, et al. Regulation of abdominal adiposity by probiotics (Lactobacillus gasseri SBT2055) in adults with obese tendencies in a randomized controlled trial. Eur J Clin Nutr 2010;64:636-43.

47. Kim J, Yun JM, Kim MK, Kwon O, Cho B. Lactobacillus gasseri BNR17 supplementation reduces the visceral fat accumulation and waist circumference in obese adults: a randomized, double-blind, placebo-controlled trial. J Med Food 2018;21: 454-61.

48. Pedret A, Valls RM, Calderón-Pérez L, Llauradó E, Companys J, Pla-Pagà L, et al. Effects of daily consumption of the probiotic Bifidobacterium animalis subsp. lactis CECT 8145 on anthropometric adiposity biomarkers in abdominally obese subjects: a randomized controlled trial. Int J Obes (Lond) 2019; 43:1863-8.

49. Sanchis-Chordà J, Del Pulgar EM, Carrasco-Luna J, BenítezPáez A, Sanz Y, Codoñer-Franch P. Bifidobacterium pseudocatenulatum CECT 7765 supplementation improves inflammatory status in insulin-resistant obese children. Eur J Nutr 2019; 58:2789-800.

50. Szulińska M, Łoniewski I, van Hemert S, Sobieska M, Bogdański P. Dose-dependent effects of multispecies probiotic supplementation on the lipopolysaccharide (LPS) level and cardiometabolic profile in obese postmenopausal women: a 12-week randomized clinical trial. Nutrients 2018;10:E773.

51. Brahe LK, Astrup A, Larsen LH. Can we prevent obesity-related metabolic diseases by dietary modulation of the gut microbiota? Adv Nutr 2016;7:90-101.

52.Lazar V, Ditu LM, Pircalabioru GG, Picu A, Petcu L, Cucu N, et al. Gut microbiota, host organism, and diet trialogue in diabetes and obesity. Front Nutr 2019;6:21.

53. Meijnikman AS, Gerdes VE, Nieuwdorp M, Herrema H. Evaluating causality of gut microbiota in obesity and diabetes in humans. Endocr Rev 2018;39:133-53.

54. Díaz-Rizzolo DA, Kostov B, López-Siles M, Serra A, Colungo 
C, González-de-Paz L, et al. Healthy dietary pattern and their corresponding gut microbiota profile are linked to a lower risk of type 2 diabetes, independent of the presence of obesity. Clin Nutr 2019 Mar 4 [Epub]. https://doi.org/10.1016/j.clnu.2019. 02.035

55. Statovci D, Aguilera M, MacSharry J, Melgar S. The impact of Western diet and nutrients on the microbiota and immune response at mucosal interfaces. Front Immunol 2017;8:838.

56. Tomova A, Bukovsky I, Rembert E, Yonas W, Alwarith J, Barnard ND, et al. The effects of vegetarian and vegan diets on gut microbiota. Front Nutr 2019;6:47.

57. Glick-Bauer M, Yeh MC. The health advantage of a vegan diet: exploring the gut microbiota connection. Nutrients 2014;6: 4822-38.

58. Garcia-Mazcorro JF, Noratto G, Remes-Troche JM. The effect of gluten-free diet on health and the gut microbiota cannot be extrapolated from one population to others. Nutrients 2018; 10;E1421.

59. De Palma G, Nadal I, Collado MC, Sanz Y. Effects of a glutenfree diet on gut microbiota and immune function in healthy adult human subjects. Br J Nutr 2009;102:1154-60.

60. Bonder MJ, Tigchelaar EF, Cai X, Trynka G, Cenit MC, Hrdlickova $B$, et al. The influence of a short-term gluten-free diet on the human gut microbiome. Genome Med 2016;8:45.

61. Sloan TJ, Jalanka J, Major GA, Krishnasamy S, Pritchard S, Abdelrazig S, et al. A low FODMAP diet is associated with changes in the microbiota and reduction in breath hydrogen but not colonic volume in healthy subjects. PLoS One 2018; 13:e0201410.

62. Staudacher HM, Whelan K. The low FODMAP diet: recent advances in understanding its mechanisms and efficacy in IBS. Gut 2017;66:1517-27.

63. Garcia-Mantrana I, Selma-Royo M, Alcantara C, Collado MC. Shifts on gut microbiota associated to Mediterranean diet adherence and specific dietary intakes on general adult population. Front Microbiol 2018;9:890.

64. Coelho OG, Cândido FG, Alfenas RC. Dietary fat and gut microbiota: mechanisms involved in obesity control. Crit Rev Food Sci Nutr 2019;59:3045-53.

65. Baik I. Forecasting obesity prevalence in Korean adults for the years 2020 and 2030 by the analysis of contributing factors. Nutr Res Pract 2018;12:251-7.

66. Lim MY, Rho M, Song YM, Lee K, Sung J, Ko G. Stability of gut enterotypes in Korean monozygotic twins and their association with biomarkers and diet. Sci Rep 2014;4:7348. 